\title{
Reliability and Economic Effects of Maintenance on TNEP Considering Line Loading and Repair
}

\author{
Meisam Mahdavi, Hassan Monsef, Member, IEEE, and Ruben Romero, Senior Member, IEEE
}

\begin{abstract}
This paper takes into account the reliability and economic effects of line maintenance on the transmission network expansion planning considering line repairs and the reliability effect of line loadings. For this purpose, a quantitative relationship between line lifetimes and the value of the transmission system is introduced in order to formulate the economic effect of maintenance. Also, the failure rate and mean time to repair coefficients are employed to calculate reliability effects of line maintenance using the cost of load shedding. Furthermore, the effect of line loadings on transmission system reliability is formulated through the line failure rates. The proposed model is tested on the Garver's network and the IEEE Reliability Test System, which is followed by a discussion of the results.
\end{abstract}

Index Terms-Line loading, line maintenance and repair, power system reliability, transmission expansion planning.

\section{NOMENCLATURE}

Sets:

$(i j)$

$\Omega^{b}, \Omega^{c}$

Line $j$ of corridor $i$.

$\Omega^{e c}, \Omega^{s}$

Set of all buses and all corridors.

Set of existing corridors and corridors, including substations.

$\Omega^{l b}, \Omega^{g b}$

Set of load buses and generation buses.

Constants:

$\hat{a}_{f, n m}^{z}, \hat{b}_{q, n m}^{z}$

The ratio of the change in power flow on the line connected between buses $n$ and $m$ to the change in generation on bus $f$ and to the change in demand on bus $q$ when element $z$ fails.

$B_{z}(x)$
Effective age of element $z$ at the end of the $x^{\text {th }}$ mission (year).
$C^{L}$

$C_{i}^{C}, C_{i}^{S}$

$\underline{C_{z}^{M}}, \underline{C_{z}^{r}}$

$C_{i}^{R}$

$\ell_{i}, V_{i}$

$\delta_{z}$

Manuscript received October 11, 2014; revised March 04, 2015; accepted September 25, 2015. Date of publication November 03, 2015; date of curren version August 17, 2016. Paper no. TPWRS-01397-2014. (Corresponding author: Ruben Romero.)

M. Mahdavi and H. Monsef are with the Research Center of Power System Operation and Planning Studies, School of Electrical and Computer Engineering, College of Engineering, University of Tehran, Tehran 14395-515, Iran (e-mail:me.mahdavi@ut.ac.ir, hmonsef@ut.ac.ir ).

R. Romero is with the Department of Electrical Engineering, Faculty of Engineering of Ilha Solteira, Paulista State University, Ilha Solteira 15385-000, SP, Brazil (e-mail: ruben@dee.feis.unesp.br).

Color versions of one or more of the figures in this paper are available online at http://ieeexplore.ieee.org.

Digital Object Identifier 10.1109/TPWRS.2015.2487322
$D_{n}, G_{n}$

$k^{L}$

$\overline{n_{i}}, \underline{n_{i}}$

$n_{z}^{l 0}, n_{z}^{r l}$

$\overline{P_{i}}, \overline{P_{n m}}$

$r_{i}{ }^{\prime}, \gamma_{i}{ }^{\prime}$

$T$

$\operatorname{VOLL} L_{n}$

$\underline{\lambda_{z}}, \underline{\tau_{z}}$

$\underline{\mu_{z}}$

Variables:

$L S_{n z}$

$n_{i}, n_{i}^{s}$

Per unit cost of power losses (\$/MWh).

Construction cost of a line circuit and a substation $138 / 230 \mathrm{kV}$ in corridor $i(\$)$.

Fixed maintenance and repair cost of element $z(\$)$.

Replacement cost of a line circuit in corridor $i$ (\$).

Total demand and generation on bus $n$ (MW).

Losses coefficient.

Length $(\mathrm{km})$ and voltage level $(\mathrm{kV})$ of corridor $i$.

Maximum and initial number of circuits in corridor $i$.

Initial operation period and regular life of element $z$ (year).

Maximum permissible active power of corridor $i$ and maximum permissible active power transmitted from bus $n$ to $m$ (MW).

Resistance $(\Omega / \mathrm{km})$ and susceptance $\left(\Omega^{-1} / \mathrm{km}\right)$ of each circuit per kilometer of corridor $i$.

Planning horizon (year).

Value of lost load (VOLL) for bus $n$ (\$/MW).

Basic value of failure rate (1/year) and mean time to repair (MTTR) (h) of element $z$.

Basic value of annual number of repairs for element $z$.

Salvage value factor of element $z$.

Load shedding of bus $n$ due to outage of element $z(\mathrm{MW})$.

Number of new circuits and substations in corridor $i$.

$n_{z}^{l e} \quad$ Life expectancy of element $z$ (year).

$\Delta \theta_{i}$
Difference between voltage phase angle of start and end buses in corridor $i$ (radian). 


\section{Functions:}

\begin{tabular}{|c|c|}
\hline$A_{z}(x)$ & $\begin{array}{l}\text { Effective age of element } z \text { after maintenance } \\
\text { actions until the end of the } x^{\text {th }} \text { mission } \\
\text { (year). }\end{array}$ \\
\hline$C_{z}^{M}, C_{z}^{r}$ & $\begin{array}{l}\text { Total maintenance and repair cost of element } \\
z(\$) \text {. }\end{array}$ \\
\hline$k_{z}, k_{z}^{r}$ & $\begin{array}{l}\text { Maintenance and repair cost coefficient for } \\
\text { element } z \text {. }\end{array}$ \\
\hline$P_{i}, P_{n m}$ & $\begin{array}{l}\text { Active power of corridor } i \text { and active power } \\
\text { transmitted from bus } n \text { to } m(\mathrm{MW}) \text {. }\end{array}$ \\
\hline $\operatorname{Pr}_{z}$ & Outage probability of element $z$. \\
\hline$P^{L}$ & Active power losses (MW). \\
\hline$P_{n m}^{z}$ & $\begin{array}{l}\text { Active power transmitted from bus } n \text { to } m \\
\text { when element } z \text { has failed (MW). }\end{array}$ \\
\hline$r_{i}, \gamma_{i}$ & $\begin{array}{l}\text { Resistance }(\Omega / \mathrm{km}) \text { and susceptance } \\
\left(\Omega^{-1} / \mathrm{km}\right) \text { per kilometer of corridor } i \text {. }\end{array}$ \\
\hline$U_{z}, A v_{z}$ & Unavailability and availability of element $z$. \\
\hline$V T S$ & $\begin{array}{l}\text { Value of transmission system at the end of } \\
\text { the planning horizon }(\$) \text {. }\end{array}$ \\
\hline$\mu_{z}$ & Annual number of repairs for element $z$. \\
\hline$\lambda_{z}, \tau_{z}$ & $\begin{array}{l}\text { Failure rate (1/year) and MTTR (h) of } \\
\text { element } z \text {. }\end{array}$ \\
\hline$\lambda_{z}^{M}$ & $\begin{array}{l}\text { Failure rate (1/year) of element } z \text { due to } \\
\text { maintenance. }\end{array}$ \\
\hline$\zeta_{z}, \chi_{z}$ & $\begin{array}{l}\text { Failure rate and MTTR coefficient of } \\
\text { element } z \text {. }\end{array}$ \\
\hline$\vartheta_{z}, \varsigma_{z}$ & $\begin{array}{l}\text { Life and depreciation coefficient of element } \\
z \text {. }\end{array}$ \\
\hline
\end{tabular}

\section{INTRODUCTION}

T HE main goal of transmission network expansion planning (TNEP) is to determine when and where new transmission lines should be installed in the network in order to help existing lines to reliably meet customer demand for electric power [1]. Nevertheless, some of the existing transmission lines may be old [2] and must be replaced by new ones. However, the replacement of old transmission lines may be costly and uneconomical over the long term. On the other hand, as the failure rates and outage probabilities of electrical components in older networks increase, transmission system reliability is reduced. This is an important challenge for planners because whereas the replacement of transmission lines is costly, retaining the old lines in the network may degrade the system's reliability, and reliability is the essential factor for long-term planning. A way to tackle this difficulty is to employ maintenance concepts, because maintenance activities could improve system reliability [3]. Recently, extensive research has been conducted on TNEP. Some of these studies have solved this problem by considering various parameters, such as reliability criteria, risk and security indices, and uncertainties. Others have investigated this problem together with generation expansion planning.

Choi et al. [4] optimized the expansion cost of the transmission network so that the total capacity of the branches involved in the minimum cut-set would be greater than or equal to the system's peak load demand. Also, they [5] minimized the investment budget for constructing new transmission lines by considering two probabilistic reliability criteria as problem constraints, as well as the uncertainties associated with the forced outage rates of the grid elements. Later, they introduced a new methodology for selecting the optimum expansion plan and level of reliability for a transmission system, which minimizes the sum of construction costs and customer outage costs [6]. Braga and Saraiva [7] presented a new formulation for the TNEP problem, but the objective function only includes expansion and generation costs and a reliability criterion: power not supplied (PNS). Akbari[8] minimized the costs of line construction, expected operation, and expected load shedding by considering load uncertainty and the voltage security constraint. Silva et al. [9] proposed a new methodology to solve the TNEP problem by considering reliability worth through the assessment of the interruption costs represented by the loss of load cost (LOLC) index. Gupta et al. [10] added reliability criteria of expected demand not served (EDNS) and expected generation not served (EGNS) to the objective function of the probabilistic transmission expansion planning problem. They showed that when EDNS is minimized, the capacity of the existing lines should be up-graded along with the addition of new transmission lines. Delgado and Claro [11] included investment cost and risk in the objective function of the TNEP problem, considering uncertainty in demand. The proposed model helps planners to balance important concerns such as network underutilization, load curtailment, and the impossibility of providing power from the cheapest generators. Orfanos et al. [12] solved the probabilistic transmission expansion planning problem considering load uncertainty and wind power generation reliability. Rahmani et al. [13] presented a new methodology based on risk/investment to solve the TNEP problem considering multiple future generation and load scenarios. The proposed model enables planners to determine the necessary funding for installing transmission lines at a permissible risk level. Lopez et al. [14] proposed a new approach for transmission system expansion considering the impact of risk management on transmission investments. In addition, Bulent Tor et al. [15] solved the TNEP problem considering transmission system security and congestion. They showed that the annual evaluation of transmission investments and congestion along with local generation investment costs ensures more realistic assessments of generation and transmission investment decisions. Furthermore, Muñoz et al. [16] modeled long-term power transmission expansion planning considering the operation costs of wind power plants. The authors investigated the variability of wind resources and the effects of wind power operation on system security. Finally, Pozo et al. [17] presented a three-level model for the expansion of an electric network. The model represents the anticipation of transmission expansion planning for the investment in generation capacity. 
However, in all of these studies, effects of the line maintenance and repair, as well as line loading on transmission system reliability and expansion costs, have not been considered; in other words, the TNEP problem has not been optimized simultaneously with maintenance and repair. It should be noted that with a low rate of maintenance, line repair cost increases and reliability may be degraded. However, if maintenance is very frequent, the repair cost decreases and reliability may be improved, but maintenance costs will increase sharply. While increasing the maintenance budget may lead to an increase in total system cost, it could forestall construction of some new lines and costly expansion of the transmission system in the future. Furthermore, power flow on the line affects line failure rates and network reliability [18]. In other words, if the power flow to the lines increases, line failure rates rise, and consequently, transmission system reliability is degraded. Meanwhile, if the magnitude of current to the lines is reduced, line failure rates decrease, thereby improving transmission system reliability. Thus, it is very useful to have a general age-dependent and loading-reliant model available that explicitly considers the economic and reliability effects of maintenance on TNEP. In this paper, a model of the line loading impact on failure rates and the maintenance effects on network reliability and transmission system value is introduced to solve the TNEP problem using the decimal codification genetic algorithm (DCGA) technique. The main aims and contributions of the present study are:

1) To present a mathematical formulation that investigates the approximate effects of line maintenance on transmission network value and repair.

2) To introduce a quantitative relationship between line maintenance, line loading, and transmission reliability.

\section{Problem Formulation}

The TNEP problem is formulated by using the DC power flow model to minimize objective function (1).

$$
\begin{aligned}
\min F_{1}= & \sum_{i \in \Omega^{c}} C_{i}^{C} n_{i}+\sum_{i \in \Omega^{s}} C_{i}^{S} n_{i}^{s} \\
& +\sum_{i \in \Omega^{e c}} C_{i}^{R}+8760 k^{L} C^{L} P^{L} \\
& +\sum_{i \in \Omega^{e c}} \sum_{j=1}^{\underline{n_{i}}}\left[C_{(i j)}^{M}+C_{(i j)}^{r}\right] \\
& +\sum_{n \in \Omega^{l b}} \operatorname{VOLL} L_{n} \sum_{i \in \Omega^{c}} \sum_{j=1}^{n_{i}+\underline{n_{i}}} L S_{n(i j)} \operatorname{Pr}_{(i j)}-V T S .
\end{aligned}
$$

Where,

$$
\begin{aligned}
\gamma_{i} & =\left(\underline{n_{i}}+n_{i}\right) \gamma_{i}^{\prime} \\
r_{i} & =\frac{r_{i}^{\prime}}{\left(\underline{n_{i}}+n_{i}\right)} \\
P^{L} & =\sum_{i \in \Omega^{c}} \frac{\ell_{i} r_{i} P_{i}^{2}}{\left|V_{i}\right|^{2}} \\
C_{(i j)}^{M} & =k_{(i j)} \frac{C_{(i j)}^{M}}{C_{(i j)}^{r}} \\
C_{(i j)}^{r} & k_{(i j)}^{r} \underline{C_{(j)}^{r}}
\end{aligned}
$$

$$
\begin{aligned}
\operatorname{Pr}_{(i j)} & =U_{(i j)} \prod_{o=1, o \neq j}^{n_{i}+\underline{n}_{i}} A v_{(i o)} \prod_{y \in \Omega^{c}} \prod_{o=1}^{n_{y}+\underline{n}_{y}} A v_{(y o)} \quad \forall y \neq i \\
& =U_{(i j)} \prod_{o=1, o \neq j}^{n_{i}+\underline{n_{i}}}\left(1-U_{(i o)}\right) \prod_{y \in \Omega^{c}} \prod_{o=1}^{n_{y}+n_{y}}\left(1-U_{(y o)}\right) \\
A v_{(i j)} & =1-U_{(i j)} \\
U_{(i j)} & =\frac{\lambda_{(i j)} \tau_{(i j)}}{\lambda_{(i j)} \tau_{(i j)}+1} \\
V T S & =\sum_{i \in \Omega^{e c}} \ell_{i} \sum_{j=1}^{n_{i}}\left[1-\left(1-\delta_{(i j)}\right) \varsigma_{(i j)}\right] C_{(i j)}^{C} \\
\varsigma_{(i j)} & =\sum_{q=1}^{n_{(i j)}^{l 0}+T} \frac{2 q}{n_{(i j)}^{l e}\left(1+n_{(i j)}^{l e}\right)} .
\end{aligned}
$$

Subject to:

$$
\begin{aligned}
G_{n} & =D_{n}+\sum_{m \in \Omega^{b}} P_{n m} \quad \forall n \in \Omega^{b}, m \neq n \\
G_{n} & =D_{n}+\sum_{m \in \Omega^{b}} P_{n m}^{(i j)}-L S_{n,(i j)} \quad \forall n \in \Omega^{b}, m \neq n \\
P_{i} & =\ell_{i} \gamma_{i} \Delta \theta_{i} \quad \forall i \in \Omega^{c} \\
\left|P_{i}\right| & \leq \overline{P_{i}} \quad \forall i \in \Omega^{c} \\
0 & \leq n_{i} \leq \overline{n_{i}}-\underline{n_{i}} \quad \forall i \in \Omega^{c} \\
0 & \leq n_{i}^{s} \leq \overline{n_{i}}-\underline{n_{i}} \quad \forall i \in \Omega^{s} \\
n_{(i j)}^{r l} & \leq n_{(i j)}^{l e} \leq 2 n_{(i j)}^{r l} \quad \forall i \in \Omega^{e c}, j=1, \ldots, \underline{n_{i}} .
\end{aligned}
$$

The first and second terms of (1) represent the construction cost of new transmission lines and substations, respectively. The third term expresses the required investment budget for replacing existing lines with new ones. Replaced transmission lines include old lines whose regular lifetimes (if the maintenance is ignored) or life expectancies (if the maintenance is considered) are less than their initial operation periods plus the planning horizon year. The fourth term represents the cost of active power losses. The fifth term describes maintenance and repair costs of the transmission network. The sixth term shows the cost of probable load curtailments due to single line outage (the calculation method of load shedding is described in Section II.A). It explains that the outage probability of a line circuit in a corridor is equal to the unavailability of that circuit multiplied by the availabilities of other circuits (both existing and new) in the same corridor and in other corridors. Finally, the seventh term indicates the value attributed to the transmission system at the end of the study period. The expansion plan must satisfy all of the constraints (12)-(18) with minimum maintenance and repair costs, and maximum transmission system value and reliability. Equation (12) indicates the DC power flow balance for each bus (node) under normal conditions (when no line outage occurs). However, (13) describes the DC power flow node balance under contingency conditions (part of the demand may be curtailed when a line fails). Equation (14) is DC power flow to transmission lines. Equation (15) explains power flow through 
each corridor is limited by maximum permissible active power of the same corridor. Equations (16)-(18) show the right-of-way constraint, maximum number of new substations and life expectancy limitation.

\section{A. Calculation Method of Load Shedding}

All terms of objective function (1) are calculated for normal conditions (when no line outage occurs) except for the sixth term. In simple terms, load shedding must be calculated after determining of proposed configuration by DCGA in each iteration. However, power flows to all lines are changed (the power flows to some lines increase, while the power flows to others decrease) when a transmission line fails. In this case, the DC power flow node balance ((12)) is no longer satisfied, because generation and demand on each bus remain fixed. Therefore, new equations are required to calculate the load curtailment of each bus with respect to its VOLL (the curtailment for loads with lower VOLLs is more possible than loads with higher VOLLs) and to balance the power flow on each bus. According to the previous statements and in light of the fact that the goal is to obtain an optimal expansion plan with the lowest cost of load curtailment (maximum reliability), objective function (19) with constraints (20)-(22) are defined in order to calculate the load shedding for each contingency state (single line outage).

$$
\min F_{2}=\sum_{n \in \Omega^{l b}} V O L L_{n} L S_{n(i j)} .
$$

Subject to:

$$
\begin{aligned}
P_{n m}^{(i j)} & =\sum_{f \in \Omega^{g b}} \hat{a}_{f, n m}^{(i j)} G_{f}+\sum_{q \in \Omega^{l b}} \hat{b}_{q, n m}^{(i j)}\left(D_{q}-L S_{q(i j)}\right) \\
\left|P_{n m}^{(i j)}\right| & \leq \overline{P_{n m}} \quad \forall n, m \in \Omega^{b}, n \neq m, i \in \Omega^{c} \\
j & =1, \ldots,\left(n_{i}+\underline{n_{i}}\right) \\
0 & \leq L S_{n(i j)} \leq D_{n} \quad \forall n \in \Omega^{l b}, i \in \Omega^{c} \\
j & =1, \ldots,\left(n_{i}+\underline{n_{i}}\right) .
\end{aligned}
$$

Equations (21) and (22) show the power flow limit on transmission lines in contingency states, as well as minimum and maximum load shedding for buses. In (20), $\hat{a}_{f, n m}^{(i j)}$ and $\hat{b}_{q, n m}^{(i j)}$ represent the ratio of the change of power flow on the line connected between buses $n$ and $m$ to the change of generation in bus $f$ and the change of demand on bus $q$, respectively, when line $j$ of corridor $i$ fails. These factors are determined by the DC power flow for each contingency [19]. It is assumed that the slack bus can compensate for changes in generation and demand in all contingencies.

\section{B. Effect of the Maintenance Cost Coefficient $\left(k_{z}\right)$ On the Life Coefficient $\left(\vartheta_{z}\right)$}

Transmission equipment has a regular lifetime under normal operational conditions if the required maintenance activities are performed. Predefined maintenance expenditures are required to carry out these activities. If the maintenance budget is more or less than this cost, the component age (life expectancy) becomes longer or shorter than its regular life, respectively [20]. This fact

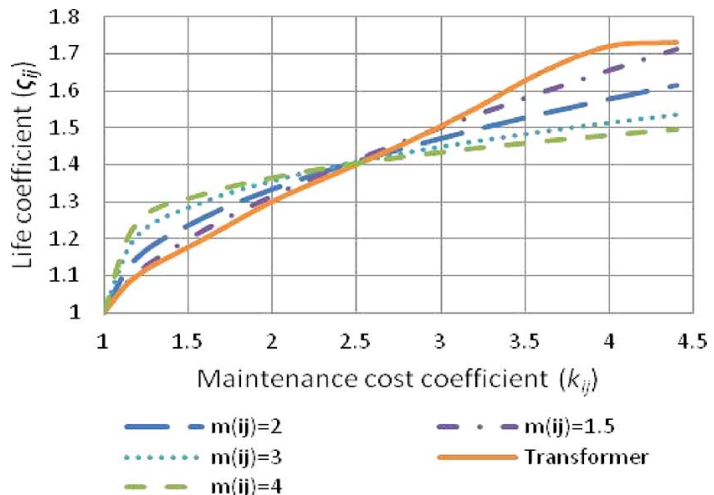

Fig. 1. Curve of life coefficient.

can be described mathematically using the age factor of element $z\left(a_{z}\right)$ as follows [20]:

$$
a_{z}=\frac{A_{z}(x)}{B_{z}(x)}=\left(\frac{C_{z}^{M}-\underline{C_{z}^{M}}}{\underline{C_{z}^{r}}}\right)^{1 / m_{z}}
$$

where $m_{z}$ is a feature of element $z$ that determines the relationship between maintenance cost and age factor. Larger and smaller $m_{z}$ correspond to younger and older elements, respectively. Rewriting (23) for the transmission lines in TNEP results in (24) as follows:

$$
a_{(i j)}=\frac{A_{(i j)}(T)}{B_{(i j)}(T)}=\left(\frac{C_{(i j)}^{M}-\underline{C_{(i j)}^{M}}}{\underline{C_{(i j)}^{r}}}\right)^{1 / m_{(i j)}} .
$$

The following algebraic equation is obtained by replacing $A_{(i j)}(T)=n_{(i j)}^{l e}-n_{(i j)}^{l 0}-T$ and $B_{(i j)}(T)=n_{(i j)}^{r l}-n_{(i j)}^{l 0}$ in (24)

$$
\begin{aligned}
\vartheta_{(i j)}=\left(1-\alpha_{(i j)}\right)\left(\beta_{(i j)}\right)^{1 / m_{(i j)}} & \left(k_{(i j)}-1\right)^{1 / m_{(i j)}} \\
& +\left(\alpha_{(i j)}+\frac{T}{n_{(i j)}^{r l}}\right) .
\end{aligned}
$$

This equation, called "curve of life coefficient," indicates the relationship between $\vartheta_{(i j)}$ and $k_{(i j)}$, where $\vartheta_{(i j)}=n_{(i j)}^{l e} / n_{(i j)}^{r l}$, $\alpha_{(i j)}=n_{(i j)}^{l 0} / n_{(i j)}^{r l}$, and $\beta_{(i j)}=\left(C_{(i j)}^{M} / C_{(i j)}^{r}\right)$. The curve is depicted in Fig. 1 for various characteristic constants $\left(m_{(i j)}\right)$, $\alpha_{(i j)}=0.6\left(n_{(i j)}^{l 0}=18\right.$ and $\left.n_{(i j)}^{r l}=30\right), \beta_{(i j)}=0.7$, and $T=12$ compared to the curve of life coefficient for a new transformer adopted from the results presented in [21].

However, $\alpha_{(i j)}$ cannot be assumed to be constant when $m_{(i j)}$ is variable, because it depends on the initial line age. It should be noted that $m_{(i j)}$ varies in the interval $\left[1, M_{(i j)}\right]$ because of $\alpha_{(i j)}$ limitation $\left(0 \leq \alpha_{(i j)} \leq 1\right)$, where $M_{(i j)}$ depends on line characteristics. Accordingly, for new lines, $\alpha_{(i j)}=0$ and $m_{(i j)}=$ $M_{(i j)}$, and for lines which are quite old, $\alpha_{(i j)}=m_{(i j)}=1$. Therefore, from Fig. 1, the aforementioned results, and the nonlinear coherence between $m_{(i j)}$ and $\alpha_{(i j)}((25))$, the following equation is deduced:

$$
m_{(i j)}=M_{(i j)}-\left(M_{(i j)}-1\right) \alpha_{(i j)}^{(1 / s)} .
$$




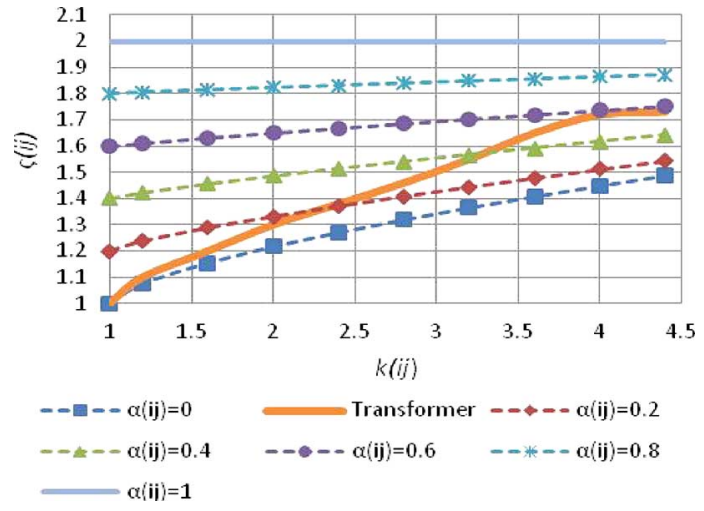

Fig. 2. Curve of life coefficient for different initial line ages.

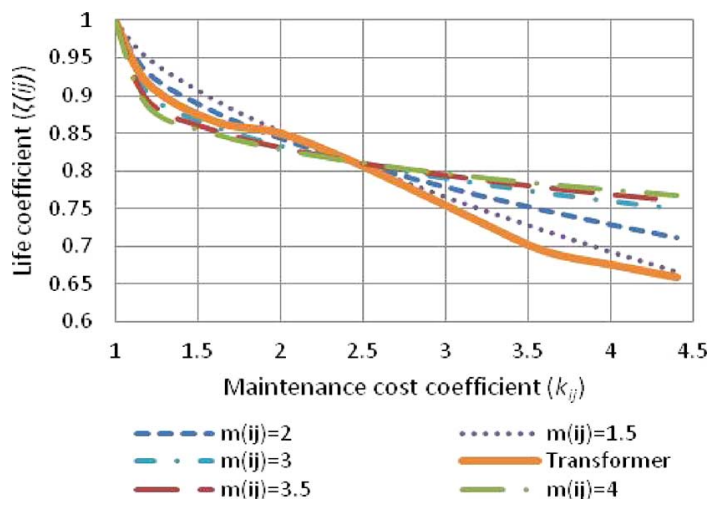

Fig. 3. Curve of failure rate.

Fig. 2 shows the results when $m_{(i j)}$ is replaced in (25). The planning horizon and regular lifetimes are considered to be 30 years, $\beta_{(i j)}=0.1, M_{(i j)}=1.5$ and $s=2$.

Fig. 2 shows that the life expectancy of lines that have been operated for longer periods increases beyond that of newer lines for the same maintenance cost coefficients. This indicates the importance of maintaining older transmission lines.

\section{Effect of $k_{z}$ on the Failure Rate Coefficient $\left(\zeta_{z}\right)$}

The transmission lines have basic failure rates under normal operational conditions if the required maintenance activities are carried out. If the maintenance costs are more or less than the cost of carrying out these activities, the failure rate becomes less or more than its basic value, respectively (Fig. 3). This can be described mathematically using curve of failure rate as follows, where $\zeta_{(i j)}=\lambda_{(i j)}^{M} / \lambda_{(i j)}($ See Appendix A).

$$
\begin{aligned}
\zeta_{(i j)}= & \left(1-\alpha_{(i j)}\right)\left(\frac{T}{n_{(i j)}^{r l}}\right) \\
& -\eta\left(1-\alpha_{(i j)}\right)\left(\beta_{(i j)}\right)^{1 / m_{(i j)}}\left(k_{(i j)}-1\right)^{1 / m_{(i j)}} .
\end{aligned}
$$

The curve is depicted in Fig. 3 for various $m_{(i j)}, \alpha_{(i j)}=0.6$, $\eta=0.468, \beta_{(i j)}=0.7$, and $T=75$ compared to the curve of the failure rate for a new transformer [21]. This curve is shown in Fig. 4 for different coefficients $\alpha_{(i j)}, T=30, \beta_{(i j)}=0.1$, and $M_{(i j)}=1.5$. Fig. 3 demonstrates the importance of line maintenance to the reliability of older transmission systems.

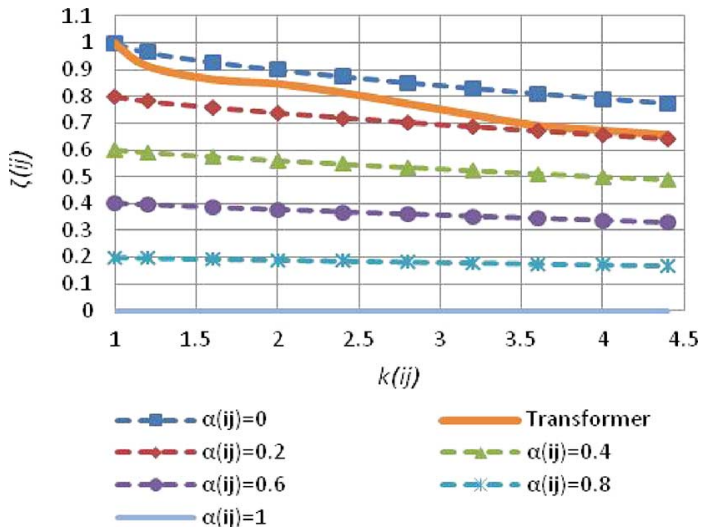

Fig. 4. Curve of failure rate for different $\alpha_{(i j)}$.

\section{Effect of $k_{z}$ on the Mean Time to Repair Coefficient $\left(\chi_{z}\right)$}

One of the aims of maintenance is to extend the mean time to repair (MTTR) because repairs may be costly [3]. In other words, if maintenance cost increases, the number of repairs may decrease. Usually, repairs to equipment are more expensive than maintenance. So, it is found that low maintenance costs do not have much effect on the number of repairs (MTTR). Conversely, if the maintenance budget is large, it may affect the MTTR considerably. So, the MTTR may increase with increases in maintenance costs until it approaches the level of repair expenditure. In this situation, the MTTR is fixed and not extended with an increase in maintenance costs (Fig. 5). Equation (28) expresses this fact mathematically (see Appendix B for more details). This algebraic equation is known as "curve of MTTR," and it explains the relationship between $\chi_{(i j)}$ and $k_{(i j)}$, where, $\chi_{(i j)}=\tau_{(i j)} / \tau_{(i j)}$. The curve is exhibited in Fig. 5 for different coefficients $\alpha_{(i j)}, \varepsilon=1(1 \leq \varepsilon \leq 4), \varpi_{1}=10.36$, $\varpi_{2}=2.216 \beta_{(i j)}=0.1, T / n_{(i j)}^{r l}=1, \mathrm{a}=2(2 \leq a<b)$, and $b=4(a<b \leq 4)$ compared to the curve of MTTR for a new transformer [21].

$$
\begin{aligned}
& \chi_{(i j)}= \\
& \left\{\begin{array}{lc}
\varpi_{1}\left(1-\frac{\alpha_{(i j)}}{2}\right)\left(\beta_{(i j)}\right)^{1 / m_{(i j)}}(a-1)^{1 / 2 m_{(i j)}}- \\
\varpi_{2}\left(1-\alpha_{(i j)}\right)^{2}\left(\frac{T}{n_{(i j)}^{r l}}\right)+\frac{\alpha_{(i j)}}{\varepsilon} & 1 \leq k_{(i j)}<a \\
\varpi_{1}\left(1-\frac{\alpha_{(i j)}}{2}\right)\left(\beta_{(i j)}\right)^{1 / m_{(i j)}}\left(k_{(i j)}-1\right)^{1 / 2 m_{(i j)}}- \\
\varpi_{2}\left(1-\alpha_{(i j)}\right)^{2}\left(\frac{T}{n_{(i j)}^{r l}}\right)+\frac{\alpha_{(i j)}}{\varepsilon} & a \leq k_{(i j)} \leq b \\
\varpi_{1}\left(1-\frac{\alpha_{(i j)}}{2}\right)\left(\beta_{(i j)}\right)^{1 / m_{(i j)}}(b-1)^{1 / 2 m_{(i j)}}- & \\
\varpi_{2}\left(1-\alpha_{(i j)}\right)^{2}\left(\frac{T}{n_{(i j)}^{r l}}\right)+\frac{\alpha_{(i j)}}{\varepsilon} & k_{(i j)}>b
\end{array}\right.
\end{aligned}
$$

According to Fig. 5, the curve of MTTR for a new transformer is nearly flat when $k_{(i j)}$ is less than 2 and greater than 4 . In other words, maintenance action does not have much effect on the MTTR curve of a transformer in this area. A power transformer is more expensive and needs more repairs and inspections than a kilometer of transmission line, so this flat area is larger for a line. Thus, constants $a$ and $b$ should be selected to be more than 2 and less than 4, respectively. However, in this paper, 2 


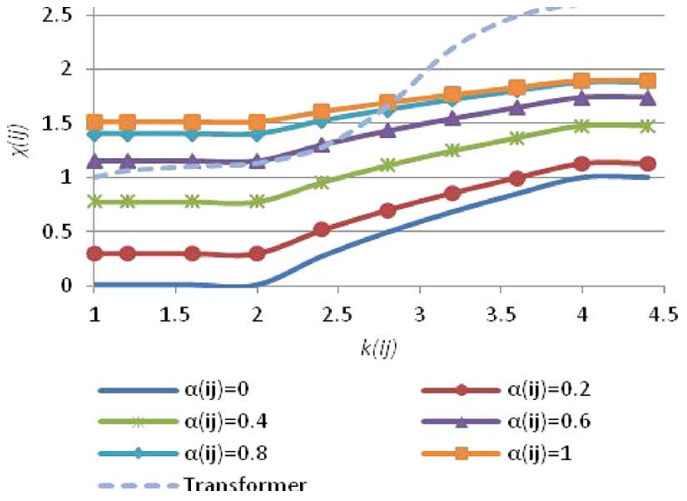

Fig. 5. Curve of MTTR for different $\alpha_{(i j)}$.

and 4 are assumed in order to compare the curves of MTTR for existing lines with the curve of MTTR for a new transformer.

\section{E. Effect of the Repair Cost Coefficient $\left(k_{z}^{r}\right)$ on $\chi_{z}$}

Along with maintenance efforts, predefined repair activities are required to provide regular lifetimes for existing transmission lines during the operation period. A specific expenditure, known as the "fixed repair cost," is necessary to perform these activities. The number of repairs, and therefore the total repair cost, decreases by increasing the maintenance cost. Also, the total repair cost is reduced as the fixed repair cost diminishes. This fact can be described analytically as follows:

$$
C_{(i j)}^{r}=\frac{C_{(i j)}^{r}}{\underline{\mu_{(i j)}}} \mu_{(i j)} .
$$

Replacing $\mu_{(i j)}=8760 / \tau_{(i j)}$ and $\underline{\mu_{(i j)}}=8760 / \underline{\tau}_{(i j)}$ in yields:

$$
C_{(i j)}^{r}=\frac{C_{(i j)}^{r}}{\overline{\tau_{(i j)}}} \tau_{(i j)}=\frac{C_{(i j)}^{r}}{\overline{\chi_{(i j)}}} .
$$

Equation (31) is obtained by comparing (30) to (6).

$$
\chi_{(i j)}=\frac{1}{k_{(i j)}^{r}} .
$$

\section{F. Effect of Line Loading on the Line Failure Rate $\left(\lambda_{(i j)}\right)$}

The magnitude of line currents affects network reliability through line failure rates [18]. In other words, line failure rates are reduced, and consequently, transmission system reliability is improved by decreasing the power flow to the lines. It is assumed that when the power transmitted through a line is zero, any transmission line $j$ in corridor $i$ has the lowest failure rate of $\lambda_{(i j)}^{M}$. If the power transmitted through a line reaches its maximum amount $\left(\overline{P_{(i j)}}\right)$, its failure rate increases to the basic value $\left(\lambda_{(i j)}\right)$. If the active power of a branch is between its minimum and maximum value, the failure rate is defined through a linear relationship to the percentage of line loading. Thus, the line loading coefficient of the $j$ th branch in corridor $i$ is defined as (32).

$$
\rho_{(i j)}=\frac{P_{(i j)}}{\bar{P}_{(i j)}} .
$$

Therefore, new failure rates of the existing transmission lines are computed as follows:

$$
\lambda_{(i j)}=\rho_{(i j)}\left(\underline{\lambda_{(i j)}}-\lambda_{(i j)}^{M}\right)+\lambda_{(i j)}^{M} .
$$

\section{Solution Method}

In the present study, the decimal codification genetic algorithm (DCGA) technique [22] is used to solve the objective function (1). This algorithm generally includes the three fundamental genetic operators of reproduction, crossover, and mutation. These operators conduct the chromosomes toward better fitness (objective function). In the first step, an initial population with $d$ chromosomes is constructed randomly as (34) when constraints (16)-(18) are satisfied.

$$
X=\left[\begin{array}{c}
X_{1} \\
X_{2} \\
X_{3} \\
\cdot \\
\cdot \\
X_{d}
\end{array}\right] .
$$

In (34), $X_{d}$ is $d$ th chromosome of the population $X$. This vector consists of integer numbers; each of them is called a "gene". These genes describe the problem variables.

$$
\begin{aligned}
X_{d}=\left[n_{1}, \ldots, n_{i}, \ldots, n_{\left|\Omega^{c}\right|}, n_{1}^{s}\right. \\
\left.\quad \ldots, n_{i}^{s}, \ldots, n_{\left|\Omega^{s}\right|}^{s}, n_{1}^{l e}, \ldots, n_{i}^{l e}, \ldots, n_{\left|\Omega^{s \mid}\right|}^{l e}\right] .
\end{aligned}
$$

Where, $n_{i}, n_{i}^{s}$, and $n_{i}^{l e}$ indicate the number of new circuits, new substations, and life expectancy of the existing lines in corridor $i$, respectively.

$$
\begin{aligned}
& n_{i}=\left\{0,1, \ldots, \overline{n_{i}}-\underline{n_{i}}\right\} \quad \forall i \in \Omega^{c} \\
& n_{i}^{s}=\left\{0,1, \ldots, \overline{n_{i}}-\underline{n_{i}}\right\} \quad \forall i \in \Omega^{s} \\
& n_{i}^{l e}=\left\{n_{(i 1)}^{l e}, n_{(i 2)}^{l e}, \ldots n_{(i j)}^{l e}, \ldots, n_{\left(\underline{i_{i}}\right)}^{l e}\right\} \forall i \in \Omega^{e c} .
\end{aligned}
$$

In (38), $n_{(i j)}^{l e}$ is the life expectancy for line $j$ of corridor $i$. Equation (39) describes a typical population with 5 chromosomes $(d=5)$ for Garver's network [22]. This 6-bus system includes 15 corridors and 6 existing transmission lines (corridors 1 (1-2), 3 (1-4), 4 (1-5), 6 (2-3), 7 (2-4), 11 (3-5)).

$X_{1}=[3,2,2,3,0,3,0,2,1,4,0,3,4,4,3,37,37,32,33,49,36]$

$X_{2}=[2,2,1,3,1,3,2,3,1,2,3,1,4,3,0,55,36,35,59,43,40]$

$X_{3}=[1,3,3,1,2,2,0,0,1,0,1,3,0,0,3,40,41,42,48,34,32]$

$X_{4}=[3,0,0,0,2,0,1,3,3,3,0,2,2,1,0,44,56,58,38,35,56]$

$X_{5}=[3,3,3,2,2,0,2,3,4,1,1,4,1,4,4,37,49,59,50,56,31]$.

$X_{1}$ proposes three new $230 \mathrm{kV}$ transmission circuits for corridors $1,4,6,12$ (3-6), and 15 (5-6), two new $230 \mathrm{kV}$ transmission circuits for corridors $2(1-3), 3$, and $8(2-5)$, four new 230 $\mathrm{kV}$ transmission circuits for corridors $10(3-4), 13(4-5)$, and 14 (4-6), and no new transmission circuits for corridors 5 (1-6), 7 , and 11. In addition, the life expectancies of the existing lines in corridors $1,3,4,6,7$, and 11 are 37, 37, 32, 33, 49 and 36 years, respectively. 
Equation (4) is calculated considering constraints (12) and (14) using DC power flow. If (15) is satisfied, objective function (19) considering constraints (20)-(22) is solved using the fmincon function for contingency states (line outages). fmincon is a function in the optimization tool box of MATLAB that can be used for minimizing constrained nonlinear multivariable problems. For Garver's network, the objective function (19) is written as (40) when first line (circuit) of corridor 1 fails.

$$
\begin{aligned}
& \min F_{2}=V O L L_{1} L S_{1(11)}+V O L L_{2} L S_{2(11)} \\
& +V O L L_{3} L S_{3(11)}+V O L L_{4} L S_{4(11)}+V O L L_{5} L S_{5(11)}
\end{aligned}
$$

Subject to:

$$
\begin{aligned}
& P_{12}^{(11)}= \sum_{f=1,3,6} \hat{a}_{f, 12}^{(11)} G_{f}+\sum_{q=1}^{5} \hat{b}_{q, 12}^{(11)}\left(D_{q}-L S_{q(11)}\right) \\
& \vdots \\
& P_{56}^{(11)}= \sum_{f=1,3,6} \hat{a}_{f, 56}^{(11)} G_{f}+\sum_{q=1}^{5} \hat{b}_{q, 56}^{(11)}\left(D_{q}-L S_{q(11)}\right) \\
&\left|P_{12}^{(11)}\right| \leq \overline{P_{12}} \vdots \\
&\left|P_{56}^{(11)}\right| \leq \overline{P_{56}} \\
& 0 \leq L S_{1(11)} \leq D_{1}, \quad 0 \leq L S_{2(11)} \leq D_{2}, 0 \leq L S_{3(11)} \leq D_{3} \\
& 0 \leq L S_{4(11)} \leq D_{4}, \quad 0 \leq L S_{5(11)} \leq D_{5} .
\end{aligned}
$$

Coefficients $\hat{a}_{f, n m}^{(11)}$ and $\hat{b}_{q, n m}^{(11)}$ for $f=1,2,3, q=1, \ldots, 5$, and $n=m=1, \ldots, 6 \forall n \neq m$ are determined by the DC power flow, and variables $L S_{1(11)}, L S_{2(11)}, L S_{3(11)}, L S_{4(11)}$ and $L S_{5(11)}$ are calculated by the fmincon function. In the next step, the second line of corridor 1 fails, and coefficients $\hat{a}_{f, n m}^{(12)}$ and $\hat{b}_{q, n m}^{(12)}$ as well as (40)-(43), are calculated. This process is iterated until all load sheddings are computed. Then, (5)-(11) are calculated, and consequently, objective function (1) is determined. Afterward, the selection operator selects the chromosomes $\left(X_{d}\right)$ in the population that are more fit for reproduction. The reproduction operator reproduces each chromosome in proportion to the value of its objective function $((1))$. Therefore, it is more probable that the chromosomes with better objective functions will be selected for the next population, rather than other chromosomes. After the pairs of parent chromosomes have been selected, the crossover operator is applied to each of these pairs. In this method, the crossover can take place at the boundary of two integer numbers (between two variables). Based on a predefined probability, known as the crossover probability $\left(P_{C}\right)$, an even number of chromosomes are chosen at random. Random positions are chosen for each pair of the selected chromosomes, and then the two chromosomes of each pair swap their genes (variables). In this paper, the crossover is used with a probability of $0.9\left(P_{C}=0.9\right)$. Equations (44) and (45) show a pair of the selected chromosomes $X_{2}$ and $X_{3}$ before and after the crossover operator is applied, respectively.

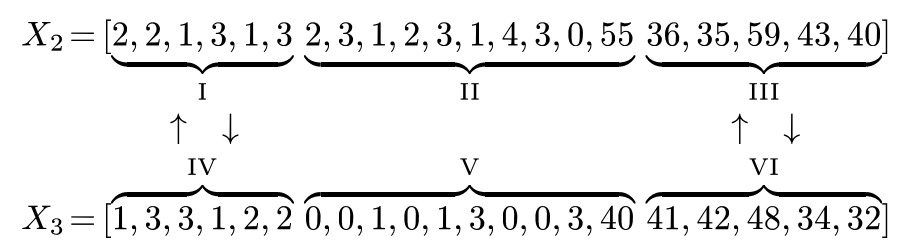

$$
\begin{aligned}
& X_{2}^{\prime}=\overbrace{1,3,3,1,2,2}^{\mathrm{IV}} \underbrace{2,3,1,2,3,1,4,3,0,55}_{\mathrm{II}} \overbrace{41,42,48,34,32}^{\mathrm{VI}}] \\
& X_{3}^{\prime}=[\underbrace{2,2,1,3,1,3}_{\text {I }} \overbrace{0,0,1,0,1,3,0,0,3,40}^{\mathrm{V}} \underbrace{36,35,59,43,40}_{\text {III }}] .
\end{aligned}
$$

Each chromosome resulting from the crossover operation will now be subject to the mutation operator in the final step of forming the new generation. This operator selects a few existing integer numbers (variables) in the chromosome and then changes their values at random according to small probability known as a mutation probability $\left(P_{M}\right)$. It should be mentioned that in this process, (16)-(18) must be satisfied, i.e., the values must not exceed their limits. In this study, mutation is applied with a probability of $0.1\left(P_{M}=0.1\right)$. Equations (46) and (47) exhibit $X_{2}$ before and after mutation, respectively.

$$
\begin{aligned}
& X_{2}^{\prime} \\
& =[1,3,3,1,2,2,2,3,1,2,3,1,4,3,0,55,41,42,48,34,32]
\end{aligned}
$$

$X_{2}^{\prime \prime}$

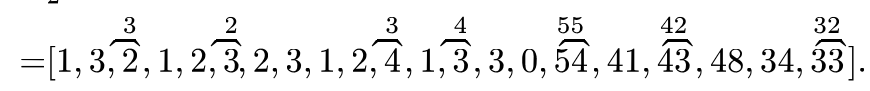

After mutation, the production of the new generation is complete, and the process can begin all over again with the evaluation of objective function (1) for each chromosome. The process continues and is terminated either by setting a target value for the fitness function to be achieved, or by setting a definite number of generations to be produced. The flowchart of the proposed method is shown in Fig. 6.

In this study, a more suitable termination criterion has been established: the production of a predefined number of generations after obtaining best fitness and finding no better solution. In this study, the maximum number of generations considered was 2000 and 10000 for the Garver's and RTS systems, respectively.

\section{Simulation Results}

The proposed planning technique was applied to Garver's network and the IEEE Reliability Test System (IEEE RTS). This approach can also be applied to large-scale systems. It should be mentioned that the planning horizon was 15 years for both case study networks. 


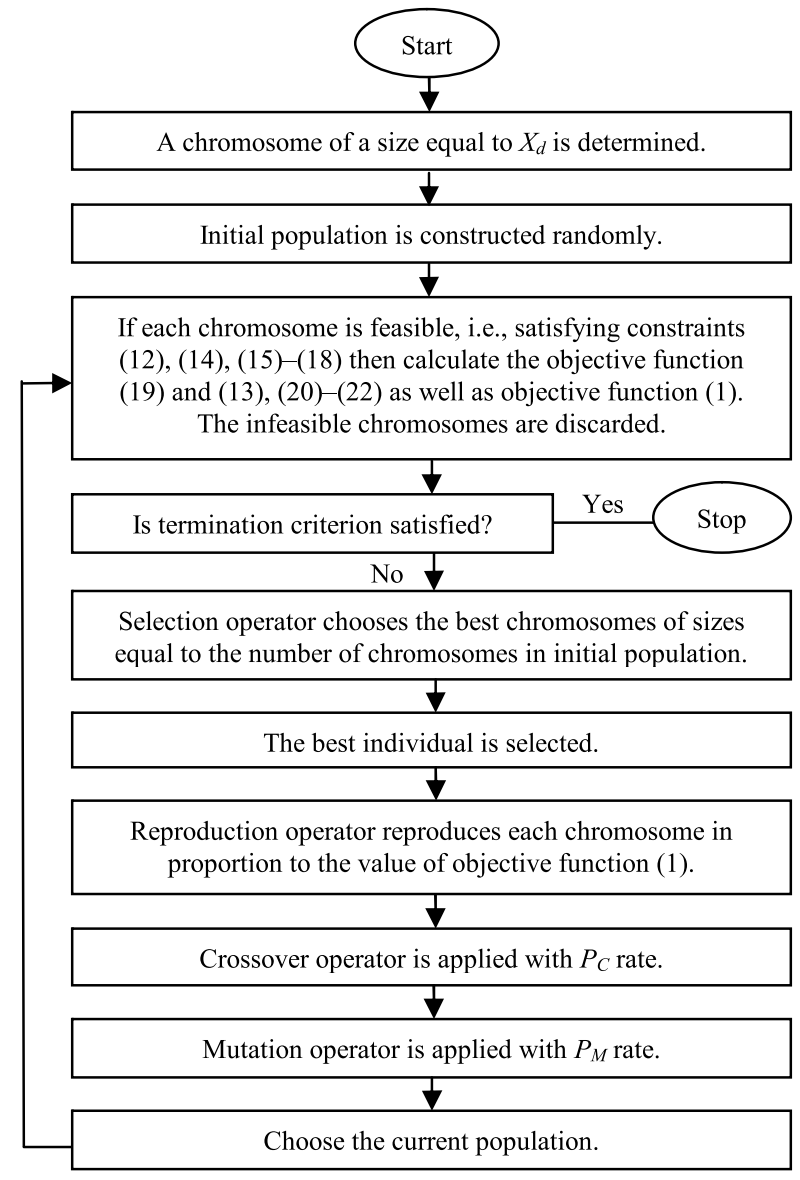

Fig. 6. Flowchart of the proposed method.

TABLE I

Reliability Data ANd Operation Periods of GarVer's Network

\begin{tabular}{c|c|c|c|c}
\hline Corridor & $n_{i}^{l 0}$ (year) & $\lambda_{i}(1 /$ year $)$ & Bus & $\operatorname{VOLL}_{n}(\$ / \mathrm{MW})$ \\
\hline $1-2$ & 5 & 0.5 & 1 & 1100 \\
\hline $1-4$ & 10 & 0.61 & 2 & 1000 \\
\hline $1-5$ & 20 & 0.42 & 3 & 1500 \\
\hline $2-3$ & 25 & 0.41 & 4 & 1200 \\
\hline $2-4$ & 15 & 0.52 & 5 & 1300 \\
\hline $3-5$ & 25 & 0.39 & 6 & - \\
\hline
\end{tabular}

\section{A. Garver's Network}

All data for this 6-bus system containing $230 \mathrm{kV}$ lines are described in [22]. The maximum number of circuits on each corridor $\left(\overline{n_{i}}\right)$, the regular life $\left(n_{i}^{r l}\right)$, and the basic value of MTTR $\left(\tau_{i}\right)$ for all transmission lines are considered to be 4,30 years, and 11 hours, respectively. Moreover, the reliability data and initial operation period $\left(n_{i}^{l 0}\right)$ of the existing lines are listed in Table I.

The proposed method was applied to the case study system in two scenarios. In Scenario 1, the TNEP problem was solved without considering line maintenance, repair, and loading effects, while in Scenario 2, these effects were considered.

1) Scenario 1: The goal was to solve the traditional TNEP problem considering fixed maintenance and repair costs $\left(_{(i j)}=k_{(i j)}^{r}=\rho_{(i j)}=1\right)$. The proposed idea was tested on the case study system. The new lines that needed to be added to the network are listed in Table II. Also, the existing corridors
TABLE II

Proposed ExPansion Plan IN SCENARIo 1 FOR GarVer's NeTWORK

\begin{tabular}{c|c|c|c|c|c|c|c|c}
\hline Corr. & $n_{i}$ & $V_{i}(\mathrm{kV})$ & Corr. & $n_{i}$ & $V_{i}$ & Corr. & $n_{i}$ & $V_{i}$ \\
\hline $2-6$ & 4 & 230 & $4-6$ & 3 & 230 & $5-6$ & 4 & 230 \\
\hline
\end{tabular}

TABLE III

COSTS (Million \$) IN SCENARIo 1 FOR GARVER'S Network

\begin{tabular}{r|c|c}
\hline \multirow{2}{*}{$\begin{array}{c}\text { Expansion cost of the } \\
\text { transmission system }\end{array}$} & Construction cost of new lines & 55.7 \\
\cline { 2 - 3 } & Replacement cost of existing lines & 5.06 \\
\hline Active losses cost & 5.92 \\
\hline Maintenance cost & 2.52 \\
\hline Repair cost & 7.2 \\
\hline Cost of probable load shedding (Reliability cost) & 1.83 \\
\hline Total cost of transmission network & 78.23 \\
\hline
\end{tabular}

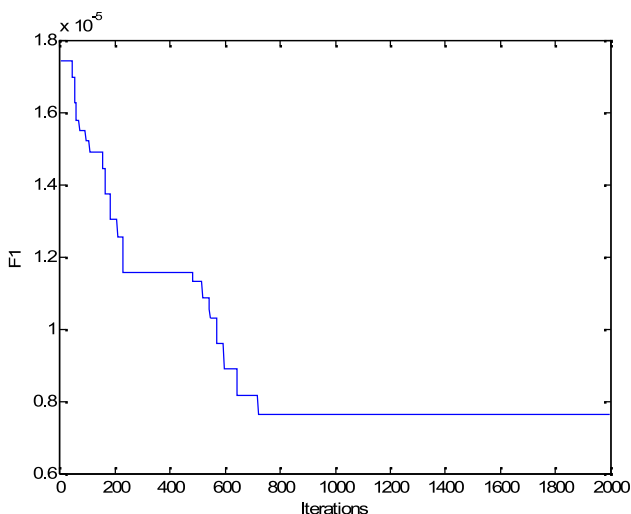

Fig. 7. Convergence curve of the algorithm for Scenario 1 of Garver's network.

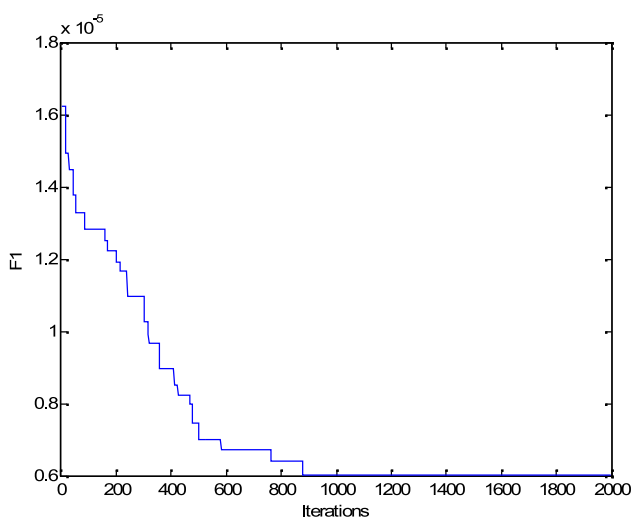

Fig. 8. Convergence curve of the algorithm for Scenario 2 of Garver's network.

$1-5,2-3$ and $3-5$ needed to be replaced by new transmission lines because of their age (See Table I). In addition, the expansion, operation, and reliability costs of the network are provided in Table III.

2) Scenario 2: In this scenario, the reliability and economic effects of line maintenance, as well as the reliability effects of line loading and repair on the TNEP problem were considered. The proposed idea was applied to the network under study, and results are provided in Tables IV-VIII. Also, the objective function values of both scenarios versus different iterations are illustrated in Figs. 7 and 8 in order to show the convergence process of the algorithm. 
TABLE IV

Proposed EXPANSION PLAN IN SCENARIO 2 FOR GARVER'S NETWORK

\begin{tabular}{c|c|c|c|c|c}
\hline Corridor & $n_{i}$ & $V_{i}(\mathrm{kV})$ & Corridor & $n_{i}$ & $V_{i}(\mathrm{kV})$ \\
\hline $2-3$ & 1 & 230 & $4-6$ & 3 & 230 \\
\hline $2-6$ & 4 & 230 & $5-6$ & 4 & 230 \\
\hline
\end{tabular}

TABLE V

New Lifetimes, FAILURE RATES, AND MTTRs FOR GARVER'S NETWORK

\begin{tabular}{c|c|c|c|c}
\hline Corridor & $n_{i}^{l e}$ & $\lambda_{i}^{M}$ & $\lambda_{i}$ & $\tau_{i}$ \\
\hline $1-2$ & 36 & 0.18 & 0.22 & 29 \\
\hline $1-4$ & 37 & 0.18 & 0.26 & 26 \\
\hline $1-5$ & 36 & 0.07 & 0.22 & 18.5 \\
\hline $2-3$ & 41 & 0.03 & 0.07 & 17.3 \\
\hline $2-4$ & 38 & 0.12 & 0.17 & 22.6 \\
\hline $3-5$ & 41 & 0.03 & 0.35 & 17.3 \\
\hline
\end{tabular}

TABLE VI

LOADING COEFFICIENTS OF EXISTING LINES IN BOTH SCENARIOS FOR GARVER'S NETWORK

\begin{tabular}{c|c|c|c|c|c}
\hline Corr. & Scenario1 & Scenario2 & Corr. & Scenario1 & Scenario2 \\
\hline $1-2$ & 0.115 & 0.12 & $2-4$ & 0.15 & 0.13 \\
\hline $1-4$ & 0.18 & 0.18 & $3-5$ & 0.95 & 0.9 \\
\hline $1-5$ & 0.45 & 0.4 & Total & 2.025 & 1.83 \\
\hline $2-3$ & 0.18 & 0.1 & - & - & - \\
\hline
\end{tabular}

TABLE VII

LoAding COEFFicients OF NeW Lines IN Both SCENARIos FOR GARVER'S NETWORK

\begin{tabular}{c|c|c|c|c|c}
\hline Corr. & Scenario & Scenario2 & Corr. & Scenario1 & Scenario2 \\
\hline $2-6$ & 0.99 & 0.99 & $5-6$ & 0.7 & 0.71 \\
\hline $4-6$ & 0.69 & 0.69 & Total & 2.38 & 2.39 \\
\hline
\end{tabular}

TABLE VIII

Costs in ScEnario 2 (Million \$) FOR GARVER's Network

\begin{tabular}{c|c|c}
\hline $\begin{array}{c}\text { Expansion cost of the } \\
\text { transmission system }\end{array}$ & Construction cost of new lines & 58.5 \\
\cline { 2 - 3 } & Replacement cost of existing lines & 0 \\
\hline \multicolumn{2}{|c}{ Active losses cost } & 5.87 \\
\hline Maintenance cost & 7.53 \\
\hline Repair cost & 5.14 \\
\hline Cost of probable load shedding (Reliability cost) & 1.65 \\
\hline Value of transmission system (VTS) & 13.95 \\
\hline Total cost of transmission network & 64.74 \\
\hline
\end{tabular}

\section{B. IEEE RTS}

This 24-bus network contains transmission lines at two voltage levels: $138 \mathrm{kV}$ and $230 \mathrm{kV}$. All data for this test system are presented in [23]. $\overline{n_{i}}$ and $n_{i}^{r l}$ for all transmission lines are considered to be 2 and 30 years, respectively. Also, $n_{i}^{l 0}$ and the value of lost load (VOLL) of the existing lines for this network are listed in Tables IX and X. The proposed method was applied to the case study without considering maintenance and repair effects (Scenario 1) and considering them (Scenario 2).

1) Scenario 1: The TNEP problem was solved considering only fixed maintenance and repair costs, network losses, and transmission system reliability. The proposed idea was tested on the IEEE RTS. New lines that needed to be added to the network are listed in Table XI. Also, 22 of the existing corridors needed to be replaced by new transmission lines (Table XII). In addition, a new $138 / 230 \mathrm{kV}$ substation needed to be constructed in corridor 3-24. The related costs are listed in Table XIII.
TABLE IX

OPERATION PERIODS OF THE LINES FOR IEEE RTS

\begin{tabular}{c|c|c|c|c|c}
\hline Corr. & $n_{i}^{l 0}$ (year) & Corr. & $n_{i}^{l 0}$ & Corr. & $n_{i}^{l 0}$ \\
\hline $1-2$ & 10 & $8-9$ & 14 & $15-24$ & 18 \\
\hline $1-3$ & 18 & $8-10$ & 18 & $16-17$ & 18 \\
\hline $1-5$ & 18 & $11-13$ & 14 & $16-19$ & 18 \\
\hline $2-4$ & 18 & $11-14$ & 18 & $17-18$ & 14 \\
\hline $2-6$ & 18 & $12-13$ & 18 & $17-22$ & 18 \\
\hline $3-9$ & 14 & $12-23$ & 18 & $18-21$ & 18 \\
\hline $4-9$ & 18 & $13-23$ & 18 & $19-20$ & 18 \\
\hline $5-10$ & 18 & $14-16$ & 18 & $20-23$ & 18 \\
\hline $6-10$ & 10 & $15-16$ & 18 & $21-22$ & 18 \\
\hline $7-8$ & 18 & $15-21$ & 14 & - & - \\
\hline
\end{tabular}

TABLE X

VALUE OF LOST LOAD (VOLL) OF BUSES FOR IEEE RTS

\begin{tabular}{c|c|c|c|c|c}
\hline Bus & VOLL $_{n}(\$ / \mathrm{MW})$ & Bus & VOLL $_{n}$ & Bus & VOLL $L_{n}$ \\
\hline 1 & 1900 & 7 & 2200 & 15 & 5550 \\
\hline 2 & 1700 & 8 & 3000 & 16 & 1750 \\
\hline 3 & 3200 & 9 & 3100 & 18 & 5850 \\
\hline 4 & 1300 & 10 & 3400 & 19 & 3250 \\
\hline 5 & 1250 & 13 & 4200 & 20 & 2250 \\
\hline 6 & 2400 & 14 & 3400 & - & - \\
\hline
\end{tabular}

TABLE XI

Proposed EXPANSION PLAN IN SCENARIO 1 FOR IEEE RTS

\begin{tabular}{c|c|c|c|c|c|c|c|c}
\hline Corr. & $n_{i}$ & $V_{i}(\mathrm{kV})$ & Corr. & $n_{i}$ & $V_{i}$ & Corr. & $n_{i}$ & $V_{i}$ \\
\hline $1-3$ & 1 & 138 & $2-8$ & 1 & 138 & $14-15$ & 1 & 230 \\
\hline $1-4$ & 1 & 138 & $5-7$ & 1 & 138 & $14-18$ & 1 & 230 \\
\hline $1-6$ & 1 & 138 & $7-8$ & 1 & 138 & $15-22$ & 1 & 230 \\
\hline $1-7$ & 1 & 138 & $11-13$ & 1 & 230 & $15-23$ & 1 & 230 \\
\hline $1-8$ & 2 & 138 & $12-16$ & 1 & 230 & $17-19$ & 1 & 230 \\
\hline $1-9$ & 1 & 138 & $13-14$ & 2 & 230 & $21-24$ & 1 & 230 \\
\hline $1-10$ & 2 & 138 & $13-20$ & 1 & 230 & $23-24$ & 1 & 230 \\
\hline
\end{tabular}

TABLE XII

LiNES RePlaced By NEW ONES IN SCENARIO 1 FOR IEEE RTS

\begin{tabular}{c|c|c|c|c|c}
\hline Corr. & $\begin{array}{c}\text { Number of } \\
\text { replaced circuits }\end{array}$ & $V_{i}$ & Corr. & $\begin{array}{c}\text { Number of } \\
\text { replaced circuits }\end{array}$ & $V_{i}$ \\
\hline $1-3$ & 1 & 138 & $13-23$ & 1 & 230 \\
\hline $1-5$ & 1 & 138 & $14-16$ & 1 & 230 \\
\hline $2-4$ & 1 & 138 & $15-16$ & 1 & 230 \\
\hline $2-6$ & 1 & 138 & $15-24$ & 1 & 230 \\
\hline $4-9$ & 1 & 138 & $16-17$ & 1 & 230 \\
\hline $5-10$ & 1 & 138 & $16-19$ & 1 & 230 \\
\hline $7-8$ & 1 & 138 & $17-22$ & 1 & 230 \\
\hline $8-10$ & 1 & 138 & $18-21$ & 2 & 230 \\
\hline $11-14$ & 1 & 230 & $19-20$ & 2 & 230 \\
\hline $12-13$ & 1 & 230 & $20-23$ & 2 & 230 \\
\hline $12-23$ & 1 & 230 & $21-22$ & 1 & 230 \\
\hline
\end{tabular}

TABLE XIII

The Costs (Million \$) IN SCENARIO 1 FOR IEEE RTS

\begin{tabular}{c|c|c}
\hline \multirow{2}{*}{$\begin{array}{c}\text { Expansion cost of the } \\
\text { transmission system }\end{array}$} & Construction cost of new lines & 58.83 \\
\cline { 2 - 3 } & Replacement cost of existing lines & 32.72 \\
\hline Expansion cost of substations & 3.5 \\
\hline Active losses cost & 12.93 \\
\hline Maintenance cost & 1.84 \\
\hline Repair cost & 5.34 \\
\hline Cost of probable load shedding (Reliability cost) & 15.04 \\
\hline Total cost of transmission network & 130.2 \\
\hline
\end{tabular}


TABLE XIV

Proposed EXPANSION PLAN IN SCENARIO 2 FOR IEEE RTS

\begin{tabular}{c|c|c|c|c|c|c|c|c}
\hline Corr. & $n_{i}$ & $V_{i}(\mathrm{kV})$ & Corr. & $n_{i}$ & $V_{i}$ & Corr. & $n_{i}$ & $V_{i}$ \\
\hline $1-2$ & 1 & 138 & $2-3$ & 1 & 138 & $14-18$ & 1 & 230 \\
\hline $1-3$ & 1 & 138 & $2-8$ & 1 & 138 & $15-22$ & 1 & 230 \\
\hline $1-4$ & 2 & 138 & $5-7$ & 1 & 138 & $15-23$ & 1 & 230 \\
\hline $1-5$ & 1 & 138 & $7-8$ & 1 & 138 & $17-19$ & 1 & 230 \\
\hline $1-6$ & 2 & 138 & $11-13$ & 1 & 230 & $17-21$ & 1 & 230 \\
\hline $1-7$ & 2 & 138 & $12-16$ & 1 & 230 & $21-24$ & 1 & 230 \\
\hline $1-8$ & 2 & 138 & $13-14$ & 2 & 230 & $23-24$ & 1 & 230 \\
\hline $1-9$ & 1 & 138 & $13-19$ & 1 & 230 & - & - & - \\
\hline $1-10$ & 2 & 138 & $13-20$ & 1 & 230 & - & - & - \\
\hline
\end{tabular}

TABLE XV

NEW LIFETIMES, FAILURE RATES, AND MTTRS FOR IEEE RTS

\begin{tabular}{c|c|c|c|c}
\hline Corridor & $n_{i}^{l e}$ & $\lambda_{i}^{M}$ & $\lambda_{i}$ & $\tau_{i}$ \\
\hline $1-2$ & 44 & 0.06 & 0.1 & 48.8 \\
\hline $1-3$ & 34 & 0.1 & 0.38 & 15.2 \\
\hline $1-5$ & 35 & 0.06 & 0.23 & 15.2 \\
\hline $2-4$ & 34 & 0.08 & 0.2 & 15.2 \\
\hline $2-6$ & 34 & 0.09 & 0.34 & 15.2 \\
\hline $3-9$ & 39 & 0.09 & 0.24 & 21.1 \\
\hline $4-9$ & 34 & 0.07 & 0.14 & 15.2 \\
\hline $5-10$ & 35 & 0.07 & 0.2 & 15.2 \\
\hline $6-10$ & 40 & 0.08 & 0.2 & 88 \\
\hline $7-8$ & 35 & 0.06 & 0.3 & 16.7 \\
\hline $8-9$ & 33 & 0.11 & 0.15 & 16.6 \\
\hline $8-10$ & 34 & 0.09 & 0.14 & 16.7 \\
\hline $11-13$ & 40 & 0.09 & 0.31 & 28.5 \\
\hline $11-14$ & 36 & 0.07 & 0.12 & 18.9 \\
\hline $12-13$ & 41 & 0.07 & 0.33 & 25.9 \\
\hline $12-23$ & 35 & 0.1 & 0.29 & 18.9 \\
\hline $13-23$ & 35 & 0.09 & 0.12 & 18.9 \\
\hline $14-16$ & 36 & 0.07 & 0.16 & 18.9 \\
\hline $15-16$ & 42 & 0.06 & 0.11 & 28.2 \\
\hline $15-21$ & 40 & 0.09 & 0.27 & 28.5 \\
\hline $15-24$ & 36 & 0.08 & 0.29 & 18.9 \\
\hline $16-17$ & 41 & 0.06 & 0.22 & 25.9 \\
\hline $16-19$ & 41 & 0.06 & 0.11 & 25.9 \\
\hline $17-18$ & 42 & 0.07 & 0.21 & 33 \\
\hline $17-22$ & 35 & 0.1 & 0.22 & 18.9 \\
\hline $18-21$ & 41 & 0.06 & 0.07 & 25.9 \\
\hline $19-20$ & 36 & 0.07 & 0.16 & 18.9 \\
\hline $20-23$ & 41 & 0.06 & 0.25 & 25.9 \\
\hline $21-22$ & 35 & 0.09 & 0.2 & 18.9 \\
\hline & & & & \\
\hline
\end{tabular}

2) Scenario 2: The problem was solved considering line maintenance, repair, and loading effects. The proposed idea was applied to the network, and results are provided in Tables XIV-XVIII. In addition, the construction of a new $138 / 230 \mathrm{kV}$ substation within corridor 3-24 was required. Moreover, the convergence process of the objective functions for both scenarios are shown in Figs. 9 and 10.

The construction costs of new lines for the plans that consider the effects of maintenance are more than those of the other configurations. The reason for this discrepancy is that, in Scenario 2, more new transmission lines must be added to the network (compare Tables IV and XIV with Tables II and XI) in order to decrease the line loadings (see Tables VI and XVI), and consequently, line failure rates (Tables $\mathrm{V}$ and $\mathrm{XV}$ ). These modifications result in network losses that are less than the active losses in Scenario 1. In addition, in Scenario 1, US\$7.18 million (US\$1.84 million for maintenance and US\$5.34 million for
TABLE XVI

LOADING COEFFICIENTS OF EXISTING LINES IN Both SCENARIOS FOR IEEE RTS

\begin{tabular}{c|c|c|c|c|c}
\hline Corr. & Scenario & Scenario2 & Corr. & Scenario1 & Scenario2 \\
\hline $1-2$ & 0.46 & 0.32 & $12-23$ & 0.42 & 0.44 \\
\hline $1-3$ & 0.89 & 0.68 & $13-23$ & 0.01 & 0.06 \\
\hline $1-5$ & 0.84 & 0.52 & $14-16$ & 0.18 & 0.3 \\
\hline $2-4$ & 0.61 & 0.41 & $15-16$ & 0.18 & 0.19 \\
\hline $2-6$ & 0.83 & 0.63 & $15-21$ & 0.6 & 0.5 \\
\hline $3-9$ & 0.68 & 0.53 & $15-24$ & 0.64 & 0.63 \\
\hline $4-9$ & 0.23 & 0.25 & $16-17$ & 0.5 & 0.56 \\
\hline $5-10$ & 0.48 & 0.5 & $16-19$ & 0.3 & 0.18 \\
\hline $6-10$ & 0.82 & 0.59 & $17-18$ & 0.79 & 0.57 \\
\hline $7-8$ & 0.96 & 0.98 & $17-22$ & 0.31 & 0.28 \\
\hline $8-9$ & 0.21 & 0.12 & $18-21$ & 0.09 & 0.02 \\
\hline $8-10$ & 0.25 & 0.16 & $19-20$ & 0.37 & 0.28 \\
\hline $11-13$ & 0.72 & 0.7 & $20-23$ & 0.72 & 0.69 \\
\hline $11-14$ & 0.12 & 0.13 & $21-22$ & 0.28 & 0.3 \\
\hline $12-13$ & 0.82 & 0.77 & Total & 14.26 & 12.41 \\
\hline
\end{tabular}

TABLE XVII

LOADING COEFFICIENTS OF NEW LINES IN BOTH SCENARIOS FOR IEEE RTS

\begin{tabular}{c|c|c|c|c|c}
\hline Corr. & Scenario & Scenario2 & Corr. & Scenario1 & Scenario2 \\
\hline $1-4$ & 0.6 & 0.5 & $13-14$ & 0.5 & 0.5 \\
\hline $1-6$ & 0.8 & 0.7 & $13-20$ & 0.3 & 0.2 \\
\hline $1-7$ & 0.1 & 0.05 & $14-18$ & 0.5 & 0.76 \\
\hline $1-8$ & 0.7 & 0.7 & $15-22$ & 0.6 & 0.6 \\
\hline $1-9$ & 0.5 & 0.4 & $15-23$ & 0.4 & 0.4 \\
\hline $1-10$ & 0.5 & 0.5 & $17-19$ & 0.6 & 0.6 \\
\hline $2-8$ & 0.7 & 0.7 & $21-24$ & 0.5 & 0.5 \\
\hline $5-7$ & 0.6 & 0.5 & $23-24$ & 0.5 & 0.5 \\
\hline $12-16$ & 0.1 & 0.27 & Total & 8.5 & 8.38 \\
\hline
\end{tabular}

TABLE XVIII

The Costs (MiLlion \$) In SCENARIo 2 FOR IEEE RTS

\begin{tabular}{r|c|c}
\hline $\begin{array}{c}\text { Expansion cost of the } \\
\text { transmission system }\end{array}$ & Construction cost of new lines & 69.17 \\
\cline { 2 - 2 } Expansion cost of substations & Replacement cost of existing lines & 0 \\
\hline \multicolumn{2}{|c|}{ Active losses cost } & 3.5 \\
\hline Maintenance cost & 11.96 \\
\hline Repair cost & 17.57 \\
\hline \multicolumn{2}{c}{ Cost of probable load shedding (Reliability cost) } & 14.96 \\
\hline Value of transmission system $(V T S)$ & 35.19 \\
\hline Total cost of transmission network & 91.79 \\
\hline
\end{tabular}

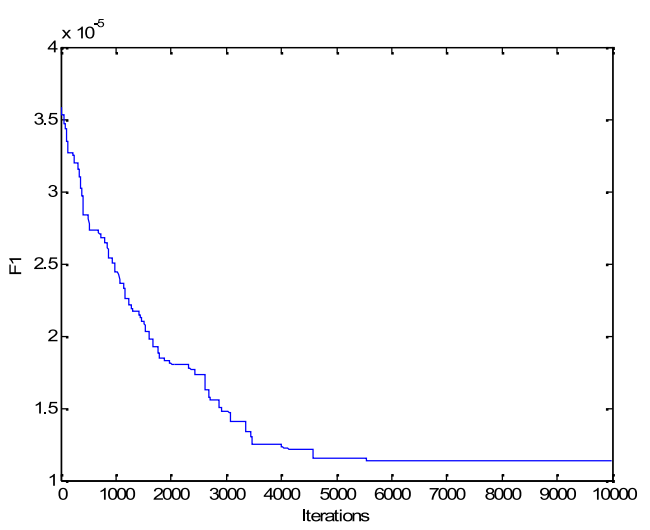

Fig. 9. Convergence curve of the algorithm for Scenario 1 of IEEE RTS.

repair) is allocated to maintain and repair the lines of existing corridors $1-2,3-9,6-10,8-9,11-13,15-21$, and 17-18 (lines 


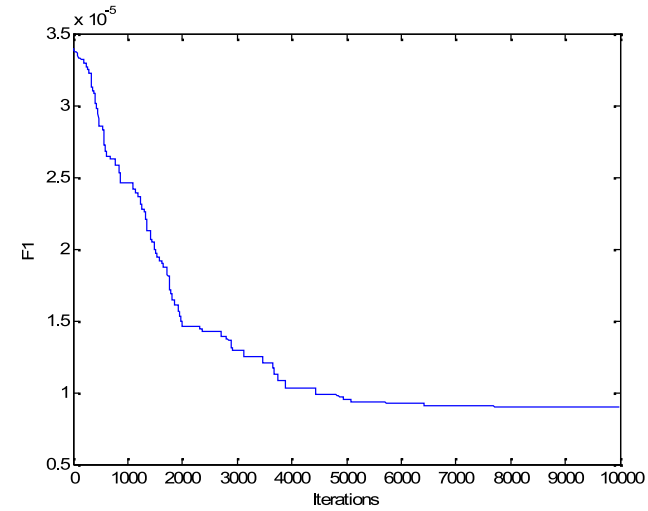

Fig. 10. Convergence curve of the algorithm for Scenario 2 of IEEE RTS.

that are not replaced by new ones because their initial operation period plus the planning horizon is smaller than or equal to their regular lifetime) in order to provide regular lifetimes for the RTS network and keep line failure rates and MTTRs at basic values. The results obtained in Scenario 1 for Garver's network confirmed this fact, because US\$9.72 million (US\$2.52 million for maintenance and US\$7.2 million for repair) was allocated to maintain and repair the existing lines of corridors $1-5$, $2-3$, and 3-5. Nevertheless, the expansion cost of the transmission system in Scenario 2 for the reliability test system was US\$22.38 million and for Garver's network US\$2.26 million less than the related costs in Scenario 1. According to Table XII, in Scenario 1, the circuits of 22 existing corridors (9 one-circuit $138 \mathrm{kV}$ lines, 10 one-circuit $230 \mathrm{kV}$ lines, and 3 two-circuit $230 \mathrm{kV}$ lines) and the circuits of 3 corridors in Garver's network ( 3 one-circuit $230 \mathrm{kV}$ lines) had to be replaced with new transmission lines because of their age (see Tables I and IX for more details). In Scenario 2, however the lifetimes of the lines in all existing corridors were extended (Tables V and XV). This increased the value of the RTS transmission system by US $\$ 35.16$ million as opposed to incurring US\$32.53 million in maintenance and repair costs with the proposed arrangement in Scenario 2. Also, the probable load shedding in Scenario 2 and Scenario 1 for the IEEE RTS were $3000 \mathrm{MW}$ and $5120 \mathrm{MW}$, and for Garver's network $1525 \mathrm{MW}$ and $1681 \mathrm{MW}$, respectively (i.e., the probable load shedding in Scenario 2 for the IEEE RTS was $2120 \mathrm{MW}$ and for Garver's network $156 \mathrm{MW}$ less than those of Scenario 1). In effect, the reliability cost of Scenario 2 was less than when the maintenance and repair effects were not considered because of the reduction of line failure rates (see Tables I, $\mathrm{V}$ and $\mathrm{XV}$, and related tables of [23]) and the modification of the transmission system. Accordingly, the total cost of the transmission network decreased from US\$130.2 million to US\$91.79 million for the reliability test system and from US\$78.23 million to US\$64.74 million for Garver's network.

From Tables VI and XVI, it seems that considering the effect of line loading on the line failure rate may result in the under-utilization of line capacity. However, reducing the difference between the total line loadings in both scenarios for new lines (compare Table XVII with Table XVI) and increasing the total loading of new transmission lines (Table VII) and the benefits to be obtained from decreasing the failure rate of existing lines can not only compensate for this deficiency, but lead to considerable cost savings. The decrease of the network losses and the cost of load shedding are part of this savings. The main part of the saved investment corresponds to the decrease in costly interruptions that may happen in the future, because the annual interruption cost of the network is equal to the failure rate (annual number of failures) multiplied by the outage duration (interruption time) (h), load shedding (MW), and cost of one MWh energy not supplied $(\$ / M W h)$. The average failure rate of each existing line in Scenario 2 for both case studies was 0.21 (Tables $\mathrm{V}$ and $\mathrm{XV}$ ). Also, the average line failure rate in Scenario 1 for the RTS system was 0.34 (see [23, Table 11]) and, 0.47 for the Garver's network (refer to Table I for more details). If it is assumed that the average interruption time of each existing line for both case study systems is $5 \mathrm{~h}$ and the cost of energy not supplied is $5000 \$ / \mathrm{MWh}$, the annual interruption costs in Scenario 2 and Scenario 1 of the RTS system would be US $\$ 15.7$ million $(5000 \times 0.21 \times 5 \times 3000)$ and US\$43.5 million $(5000$ $\times 0.34 \times 5 \times 5120)$, respectively. These amounts for Garver's network would be US\$8 million $(5000 \times 0.21 \times 5 \times 1525)$ and US $\$ 19.7$ million $(5000 \times 0.47 \times 5 \times 1681)$. Therefore, the reduction of line failure rate leads to a large amount of cost savings (US\$27.8 million for the RTS system and US\$11.7 million for the other case study) in addition to a decrease in the total cost of network losses and load shedding (US\$6 million for reliability test system and US\$230000 for Garver's network).

Overall, it can be concluded that applying the arrangements proposed in Scenario 2 is less expensive because it yields considerable cost savings compared to Scenario 1.

From Figs. 7 and 8, the solution took 719 and 879 iterations to converge for Garver's network in Scenarios 1 and 2, respectively. For this case study system, Scenario 1 had included 15 corridors and 5 load buses (buses that include load shedding), i.e., 20 independent variables (unknowns). Therefore, 719 iterations were necessary before convergence. In Scenario 2, the lifetimes of 6 existing lines, i.e., 6 new variables, were added to unknowns of Scenario 1. This fact caused the number of iteration to increase to 879 (160 more iterations). However, in Scenario 1 of the RTS system, there were 141 corridors and 17 load buses (158 variables). For this reason, the solution took 5550 iteration (7.7 times more than 719) to converge (Fig. 9), because the number of variables was 7.9 times more than number of unknowns in Scenario 1 of Garver's network. In Scenario 2 of the RTS system, the lifetimes of 29 existing lines (29 new variables) were added to independent variables of Scenario 1. In this case, the number of variables was 7.2 more than that of Scenario 2 in Garver's network. Accordingly, the number of iterations increased to 7713 .

\section{CONCLUSION}

This paper presented a reliability-based model for transmission expansion planning considering the effects of line maintenance and repair, as well as line loading, on transmission system arrangement. The economic effect of line maintenance on TNEP was formulated using the value of the transmission network and the curve of life coefficient. Its reliability effect was modeled by the cost of load shedding via the curves of failure rate and MTTR. In addition, a quantitative relationship between line loading, system reliability, and maintenance was 
introduced using failure rates and line loading coefficient. The simulation results revealed the importance of the proposed TNEP model; lines that seem old and ready to be replaced by new ones can still be economical and reliable in the long run if the required maintenance and repair actions are carried out. Although the maintenance of old lines is costly and may seem uneconomical over the short term, maintenance results in a decrease in the total cost of the transmission network over the long term because of the reduction in transmission system expansion and reliability costs and the increase in transmission system value.

\section{APPENDIX A \\ Calculation Method of $\zeta_{(i j)}$ Versus $k_{(i j)}$}

From Fig. 2 and (25), the mathematical formulation of the life coefficient for a new transformer and a new line can be expressed as (48) and (49), respectively.

$$
\begin{aligned}
\vartheta_{(\text {Transformer })} & =\beta\left(k_{(i j)}-1\right)^{2 / 3}+1 \\
\vartheta_{(i j)} & =\left(\beta_{(i j)}\right)^{2 / 3} \cdot\left(k_{(i j)}-1\right)^{2 / 3}+\frac{T}{n_{(i j)}^{r l}}
\end{aligned}
$$

where, $\beta=0.323$ and $\beta_{(i j)}=0.1$ (i.e., $\beta=(3 / 2)\left(\beta_{(i j)}\right)^{2 / 3}$ ). Also, the mathematical description of the failure rate coefficient for a new transformer is adopted from Fig. 4 as follows:

$$
\zeta_{(\text {Transformer })}=1-0.151\left(k_{(i j)}-1\right)^{2 / 3}
$$

Equation (51) shows (50) in term of $\beta$, where $\Gamma=0.468$. In simple terms, if $\Gamma$ is multiplied by $\beta$, the result is 0.151 .

$$
\zeta_{(\text {Transformer })}=1-\Gamma \beta\left(k_{(i j)}-1\right)^{2 / 3} .
$$

By comparing (51) with (48), it can be found out that the failure rate coefficient for a new transformer can be obtained when a negative coefficient such as $\Gamma$ is multiplied by $\beta$. Accordingly, the following mathematical definition can be deduced from (49), when a negative coefficient such as $\eta$ is multiplied by $\left(\beta_{(i j)}\right)^{2 / 3}$

$$
\zeta_{(i j)}=\frac{T}{n_{(i j)}^{r l}}-\eta \cdot\left(\beta_{(i j)}\right)^{2 / 3} \cdot\left(k_{(i j)}-1\right)^{2 / 3}
$$

As shown in Figs. 3 and 4, the slope of the curves for transmission lines is lower than the slope of the curve for a new transformer, therefore, the value of $\eta$ should be considered lower than $\Gamma$, i.e., $\eta=\partial_{1} \Gamma$, where $0.5 \leq \partial_{1} \leq 1$. According to (52), and by analyzing the curves of Figs. 2 and 4, the general equation of (27) can be presented. Equation (52) is a special case of (27), where $\alpha_{(i j)}=0$ and $M_{(i j)}=1.5$.

\section{APPENDIX B \\ Calculation Method of $\chi_{(i j)} \operatorname{Versus~} k_{(i j)}$}

Equation (53) approximately describes the MTTR curve of a new transformer (see Fig. 5).

$$
\begin{aligned}
& \chi_{(\text {Transformer })} \\
& \quad= \begin{cases}1 & 1 \leq k_{(i j)}<2 \\
3.346\left(k_{(i j)}-1\right)^{1 / 3}-2.216 & 2 \leq k_{(i j)} \leq 4 \\
2.63 & k_{(i j)}>4\end{cases}
\end{aligned}
$$

Equation (54) expresses (53) in term of $\beta$. It should be noted that (54) is a continuous function for all maintenance cost coefficients. In simple terms, the value of (54) is 1 for $k_{(i j)}=2$ and is 2.63 for $k_{(i j)}=4$ if $\sigma_{1}=10.36, \sigma_{2}=2.216$ and $\beta=0.323$ $\left(\beta_{(i j)}=0.1\right)$

$\chi_{(\text {Transformer })}=\left\{\begin{array}{ll}1 & 1 \leq k_{(i j)}<2 \\ \sigma_{1} \beta\left(k_{(i j)}-1\right)^{1 / 3}-\sigma_{2} & 2 \leq k_{(i j)} \leq 4 \\ 2.63 & k_{(i j)}>4\end{array}\right.$.

In (54), by replacing $\beta=(3 / 2)\left(\beta_{(i j)}\right)^{2 / 3},(3 / 2) \sigma_{1}=\varpi_{1}$, $\sigma_{2}=\varpi_{2}\left(T / n_{(i j)}^{r l}\right)\left(T / n_{(i j)}^{r l}=1\right), a=2$, and $b=4$, the continuous function (55) yields for a new line.

$$
= \begin{cases}\chi_{1}\left(\beta_{(i j)}\right)^{2 / 3}(a-1)^{1 / 3}-\varpi_{2} \frac{T}{n_{(i j)}^{r l}} & 1 \leq k_{(i j)}<a \\ \varpi_{1}\left(\beta_{(i j)}\right)^{2 / 3}\left(k_{(i j)}-1\right)^{1 / 3}-\varpi_{2} \frac{T}{n_{(i j)}^{r l}} & a \leq k_{(i j)} \leq b \\ \varpi_{1}\left(\beta_{(i j)}\right)^{2 / 3}(b-1)^{1 / 3}-\varpi_{2} \frac{T}{n_{(i j)}^{r l}} & k_{(i j)}>b\end{cases}
$$

where, $\varpi_{1}$ and $\varpi_{2}$ are coefficients of $\sigma_{1}$ and $\sigma_{2}\left(\varpi_{1}=\partial_{2} \cdot \sigma_{1}\right.$ and $\left.\varpi_{2}=\partial_{3} \cdot \sigma_{2}\right)$, and $M_{(i j)}=1.5$. Usually, values of $\varpi_{1}$ and $\varpi_{2}$ are considered to be lower than $\sigma_{1}$ and $\sigma_{2}$ because, as shown in Fig. 5, the curves of the lines have lower slopes than the ones of a new transformer $\left(0.5 \leq \partial_{2}, \partial_{3} \leq 1\right)$. According to (55), and by analyzing the curves of Figs. 2, 4 and 5, the general equation of (28) can be achieved.

\section{ACKNOWLEDGMENT}

The authors would like to thank the IEEE TPS's Editor for his valuable comments and spending time for this paper. Also, we appreciate the respected reviewers for their helpful comments and valuable suggestions. Undoubtedly, improvement of the paper without these opinions was not possible.

\section{REFERENCES}

[1] P. Murugan, "Modified particle swarm optimisation with a novel initialisation for finding optimal solution to the transmission expansion planning problem," IET Gener., Transm. Distrib., vol. 6, pp. 1132-1142, 2012.

[2] H. K. Kim, "Reliability modeling and evaluation in aging power systems," M.Sc. thesis, Electr. Comput. Eng. Dept., Texas A\&M Univ., College Station, TX, USA, 2009.

[3] P. Jirutitijaroen and C. Singh, "The effect of transformer maintenance parameters on reliability and cost: A probabilistic model," Electric Power Syst. Res., vol. 72, pp. 213-224, 2004. 
[4] J. Choi, T. Mount, and R. Thomas, "Transmission system expansion plans in view point of deterministic, probabilistic and security reliability criteria," in Proc. 39th Hawaii Int. Conf. System Sciences, 2006, vol. 10, pp. 1-10.

[5] J. Choi, T. Tran, A. A. El-Keib, R. Thomas, H. S. Oh, and R. Billinton, "A method for transmission system expansion planning considering probabilistic reliability criteria," IEEE Trans. Power Syst., vol. 20, no. 3, pp. 1606-1615, Aug. 2005.

[6] J. Choi, T. D. Mount, R. J. Thomas, and R. Billinton, "Probabilistic reliability criterion for planning transmission system expansions," Proc. Inst. Electr. Eng.-Gener., Transm. Distrib., vol. 153, pp. 719-727, 2006.

[7] A. S. D. Braga and J. T. Saraiva, "A multiyear dynamic approach for transmission expansion planning and long-term marginal costs computation," IEEE Trans. Power Syst., vol. 20, no. 3, pp. 1631-1639, Aug. 2005.

[8] A. A. Foroud, A. A. Abdoos, R. Keypour, and M. Amirahmadi, "A multi-objective framework for dynamic transmission expansion planning in competitive electricity market," Int. J. Electrical Power \& Energy Syst., vol. 32, pp. 861-872, 2010.

[9] A. M. L. Silva, L. S. Rezende, L. A. F. Manso, and L. C. Resende, "Reliability worth applied to transmission expansion planning based on ant colony system," Int. J. Electrical Power \& Energy Syst., vol. 32, pp. 1077-1084, 2010.

[10] N. Gupta, R. Shekhar, and P. K. Kalra, "Congestion management based roulette wheel simulation for optimal capacity selection: Probabilistic transmission expansion planning," Int. J. Electrical Power \& Energy Syst., vol. 43, pp. 1259-1266, 2012.

[11] D. Delgado and J. Claro, "Transmission network expansion planning under demand uncertainty and risk aversion," Int. J. Electrical Power \& Energy Syst., vol. 44, pp. 696-702, 2013.

[12] G. A. Orfanos, P. Georgilakis, and N. D. Hatziargyriou, "Transmission expansion planning of systems with increasing wind power integration," IEEE Trans. Power Syst., vol. 28, no. 2, pp. 1355-1362, May 2013.

[13] M. Rahmani, R. A. Romero, and M. J. Rider, "Risk/investment-driven transmission expansion planning with multiple scenarios," IET Gener., Transm. Distrib., vol. 7, pp. 154-165, 2013.

[14] S. Lopez, A. Aguilera, and G. Blanco, "Transmission expansion planning under uncertainty: An approach based on real option and game theory against nature," IEEE Latin America Trans.., vol. 11, pp. 566-571, 2013.

[15] O. B. Tor, A. N. Guven, and M. Shahidehpour, "Congestion-driven transmission planning considering the impact of generator expansion," IEEE Trans. Power Syst., vol. 23, no. 2, pp. 781-789, May 2008.

[16] C. Muñoz, E. Sauma, J. Contreras, J. Aguado, and S. de la Torre, "Impact of high wind power penetration on transmission network expansion planning," IET Gener., Transm. Distrib., vol. 6, pp. 1281-1291, 2012.

[17] D. Pozo, E. E. Sauma, and J. Contreras, "A three-level static MILP model for generation and transmission expansion planning," IEEE Trans. Power Syst., vol. 28, no. 1, pp. 202-210, Feb. 2013.

[18] A. H. Etemadi and M. Fotuhi-Firuzabad, "Distribution system reliability enhancement using optimal capacitor placement," IET Gener., Transm. Distrib., vol. 2, pp. 621-631, 2008.

[19] M. Jaefari-Nokandi and H. Monsef, "Scheduling of spinning reserve considering customer choice on reliability," IEEE Trans. Power Syst., vol. 24 , no. 4, pp. 1780-1789, Nov. 2009.

[20] Y. Liu and H. Z. Huang, "Optimal selective maintenance strategy for multi-state systems under imperfect maintenance," IEEE Trans. Rel., vol. 59, no. 2, pp. 356-367, Jun. 2010.

[21] "Impact of Maintenance Strategy on Reliability," Reliability, Risk and Probability Applications Subcommittee, Tech. Rep. IEEE PES Task Force on Impact of Maintenance Strategy on Reliability of the Reliability, 1999.

[22] H. Shayeghi, S. Jalilzadeh, M. Mahdavi, and H. Hadadian, "Studying influence of two effective parameters on network losses in transmission expansion planning using DCGA," Energy Conv. Manag., vol. 49, pp. 3017-3024, 2008.

[23] "IEEE reliability test system," IEEE Trans. Power App. Syst., vol. PAS-98, no. 6, pp. 2047-2054, Nov. 1979.

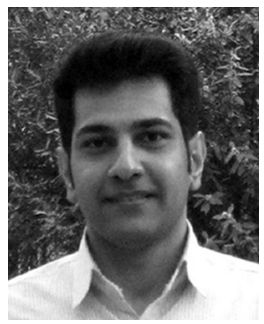

optimization

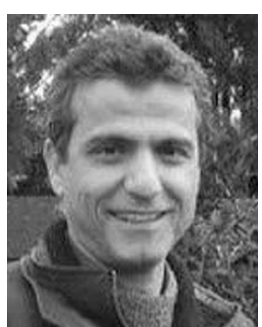

Hassan Monsef (M'15) received the B.Sc. degree from Sharif University of Technology, Tehran, Iran, in 1986, the M.Sc. (Hons.) degree from the University of Tehran, Tehran, in 1989, and the Ph.D. degree from Sharif University of Technology in 1996, all in power engineering.

$\mathrm{He}$ is currently a Professor of electrical engineering with the University of Tehran. His research interests are power system operation and planning, reliability of power system, and integration of renewables into smart grid.

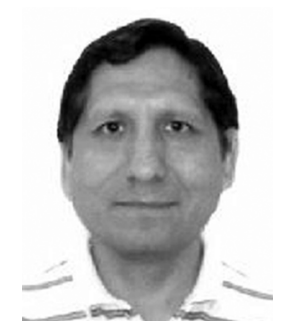

Rubén Romero (M'93-SM'08) received the B.Sc. and P.E. degrees from the National University of Engineering, Lima, Perú, in 1978 and 1984, respectively, and the M.Sc. and Ph.D. degrees from the Universidade Estadual de Campinas, Campinas, Brazil, in 1990 and 1993, respectively.

$\mathrm{He}$ is currently a Professor of electrical engineering with the Universidade Estadual Paulista "Julio de Mesquita Filho," Ilha Solteira, Brazil. His research interests include methodologies for the optimization, planning, and control of electrical power systems, applications of artificial intelligence in power system, and operations research. 